OPEN ACCESS

Edited by:

Clotilde Lecrux,

McGill University, Canada

Reviewed by:

Satoshi Saito,

National Cerebral and Cardiovascular

Center, Japan

Alla B. Salmina,

Krasnoyarsk State Medical University named after Prof. V.F.Voino-

Yasenetski, Russia

*Correspondence:

Sandra Donnini

sandra.donnini@unisi.it

Marina Ziche

marina.ziche@unisi.it

Specialty section:

This article was submitted to

Vascular Physiology,

a section of the journal

Frontiers in Physiology

Received: 03 April 2020

Accepted: 31 July 2020

Published: 27 August 2020

Citation:

Ristori E, Donnini S and Ziche M (2020) New Insights Into Blood-Brain

Barrier Maintenance: The

Homeostatic Role of $\beta$-Amyloid

Precursor Protein in

Cerebral Vasculature.

Front. Physiol. 11:1056.

doi: 10.3389/fphys.2020.01056

\section{New Insights Into Blood-Brain Barrier Maintenance: The Homeostatic Role of $\beta$-Amyloid Precursor Protein in Cerebral Vasculature}

\author{
Emma Ristori', Sandra Donnini ${ }^{1 *}$ and Marina Ziche ${ }^{2 *}$ \\ ${ }^{1}$ Department of Life Sciences, University of Siena, Siena, Italy, ${ }^{2}$ Department of Medicine, Surgery and Neuroscience, \\ University of Siena, Siena, Italy
}

Cerebrovascular homeostasis is maintained by the blood-brain barrier (BBB), a highly selective structure that separates the peripheral blood circulation from the brain and protects the central nervous system (CNS). Dysregulation of BBB function is the precursor of several neurodegenerative diseases including Alzheimer's disease (AD) and cerebral amyloid angiopathy (CAA), both related to $\beta$-amyloid $(A \beta)$ accumulation and deposition. The origin of BBB dysfunction before and/or during CAA and AD onset is not known. Several studies raise the possibility that vascular dysfunction could be an early step in these diseases and could even precede significant $A \beta$ deposition. Though accumulation of neuron-derived $A \beta$ peptides is considered the primary influence driving $A D$ and $C A A$ pathogenesis, recent studies highlighted the importance of the physiological role of the $\beta$-amyloid precursor protein (APP) in endothelial cell homeostasis, suggesting a potential role of this protein in maintaining vascular stability. In this review, we will discuss the physiological function of APP and its cleavage products in the vascular endothelium. We further suggest how loss of APP homeostatic regulation in the brain vasculature could lead toward pathological outcomes in neurodegenerative disorders.

Keywords: blood-brain barrier, $\beta$-Amyloid precursor protein, Alzheimer's disease, cerebral amyloid angiopathy, vascular homeostasis, $\beta$-Amyloid

\section{INTRODUCTION}

The brain vasculature is characterized by the presence of the blood-brain barrier (BBB), a specialized structure that maintains the separation between the circulating blood and central nervous system (CNS). The BBB surrounds most of the vessels in the brain and is characterized by the establishment of specialized endothelial tight junctions that consist of transmembrane proteins (claudin3/5, occludins, and JAMs) and cytoplasmic scaffolding proteins (e.g., ZO-1, $\mathrm{ZO}-2$, and $\mathrm{ZO}-3$ ), involved in cell-to-cell contacts and interacting with actin cytoskeleton and associated proteins (G-proteins, protein kinases, and small GTPases). The tightly interconnected endothelial cells that form the inner lining of BBB vessels not only deliver nutrients and oxygen to brain tissues to ensure neuronal function but also protect the brain by limiting entry of 
toxins, pathogen, and inflammatory cells. BBB is not the same in all the regions through the brain. While most blood vessels in the brain are situated in the $\mathrm{BBB}$, there are some regions, like the circum-ventricular organs where the microvessels are permeable and lack this specialized structure, allowing the free passage of substances (Wilhelm et al., 2016). The BBB is an essential part of the neurovascular unit (NVU), defined as a complex functional and anatomical structure composed of $\mathrm{BBB}$ endothelium, basement membranes (basal lamina and extracellular membranes), astrocytes, pericytes, microglial cells, and neurons. In this context, the neuronal-vascular interaction is critical for proper brain function, and the structural and functional integrity of blood vessels is essential to maintain appropriate brain perfusion and to preserve normal neurological function. Pathological changes in the NVU, including impairment of neurovascular coupling and BBB dysfunction, are present in a variety of neurovascular diseases (Chou et al., 2015; Cai et al., 2017; Iadecola, 2017; Liu et al., 2019; Nizari et al., 2019; Nortley et al., 2019). Increasing evidence supports the hypothesis that vascular dysfunction plays a major role in $\beta$-amyloid $(\mathrm{A} \beta)$ diseases such as cerebral amyloid angiopathy (CAA) and Alzheimer's disease (AD) (de la Torre, 2018; Klohs, 2020). While $\mathrm{AD}$ is characterized by formation of amyloid plaques in the brain parenchyma, CAA refers to $\mathrm{A} \beta$ deposits on the walls of cerebrovasculature. CAA is a common comorbidity of patients with $\mathrm{AD}$. Though accumulation of neuron-derived $\mathrm{A} \beta$ in the brain and vessel walls is considered the primary influence driving $\mathrm{CAA}$ and $\mathrm{AD}$ pathogenesis, clinical trials based on immunotherapy that target and clear $A \beta$ have failed to reverse cognitive loss. The most-cited explanation for the failure of such trials is that the drugs were given too late in the progression of the disease, when the process of $A \beta$ deposition was advanced and at a point of no return in the progression of the disease. This is due in part to an incomplete understanding of the mechanisms that trigger $A \beta$ aggregation and deposition and a lack of notions about the functional role of this peptide and its precursor protein, the amyloid precursor protein (APP) in the cerebrovascular homeostasis. Interestingly, immunotherapy with bapineuzumab, a monoclonal antibody targeting both fibrillar and soluble $\mathrm{A} \beta$, showed severe vascular adverse events like brain vasogenic edema and microhemorrhages, possibly due to a loss in cerebrovascular integrity (Gustafsson et al., 2018). This suggests that physiological levels of $A \beta$ are necessary for normal vascular homeostasis. Furthermore, several studies showed the importance of $A \beta$ and APP for proper physiological function of endothelium, and APP has been hypothesized to play a protective role in vascular dysfunction. In this work, we summarize these findings and highlight the importance of APP and its metabolites on the normal physiology of the vascular system.

\section{APP PROCESSING IN HEALTH AND DISEASE}

APP belongs to a conserved gene family that includes two mammalian homologues, the APP-like proteins (APLPs), APLP1 and APLP2. These proteins are type I integral membrane proteins that share similar structural organization and partially overlapping functions, and this may explain why single-gene-knockout animal models have failed to show any major phenotype (Shariati and De Strooper, 2013). Structurally, APP and APLPs share conserved regions, although APP is the only family member containing the sequence encoding A $\beta$ peptides (d'Uscio et al., 2017). APP presents three major isoforms, generated by alternative splicing: APP695, APP751, and APP770. The APP695 isoform is mainly expressed in neurons, whereas APP751 and APP770 are the predominant forms expressed in non-neuronal cells, including endothelial cells and platelets (Van Nostrand et al., 1994). Under physiological conditions, APP is cleaved by different secretases through two main proteolytic pathways: the amyloidogenic and non-amyloidogenic processing (Figure 1). The latter leads to the release in the extracellular space of the soluble form soluble amyloid precursor protein ( $\mathrm{APP}-\alpha)$ generated by $\alpha$-secretase (ADAM10) cleavage and the p3 peptide through cleavage of $\alpha$-secretase and the $\gamma$-secretase complex (composed of four subunits: presenilins, nicastrin, Aph-1, and Pen-2). By contrast, in the amyloidogenic processing, $\beta$-secretase (BACE1) cleavage releases soluble amyloid precursor protein cleaved by $\beta$-secretase (sAPP- $\beta$; another soluble form with different structure and physiological properties), and subsequent cleavage of BACE1 and $\gamma$-secretase generates different $A \beta$ isoforms of various lengths. Moreover, $\gamma$-secretase cleavage in the APP transmembrane region yields the biologically active APP intracellular domain (AICD) in both the proteolytic pathways. The main species of $\mathrm{A} \beta$ peptides involved in CAA and $\mathrm{AD}$ are $\mathrm{A} \beta 1-40$ and $\mathrm{A} \beta 1-42$. The $A \beta 1-42$ peptides are the predominant form in $\mathrm{AD}$ neuronal plaques, whereas deposition of $A \beta 1-40$ peptides on the cerebral vasculature contributes to the onset of CAA (Stakos et al., 2020). While the neuronal origin of $A \beta$ deposits observed in

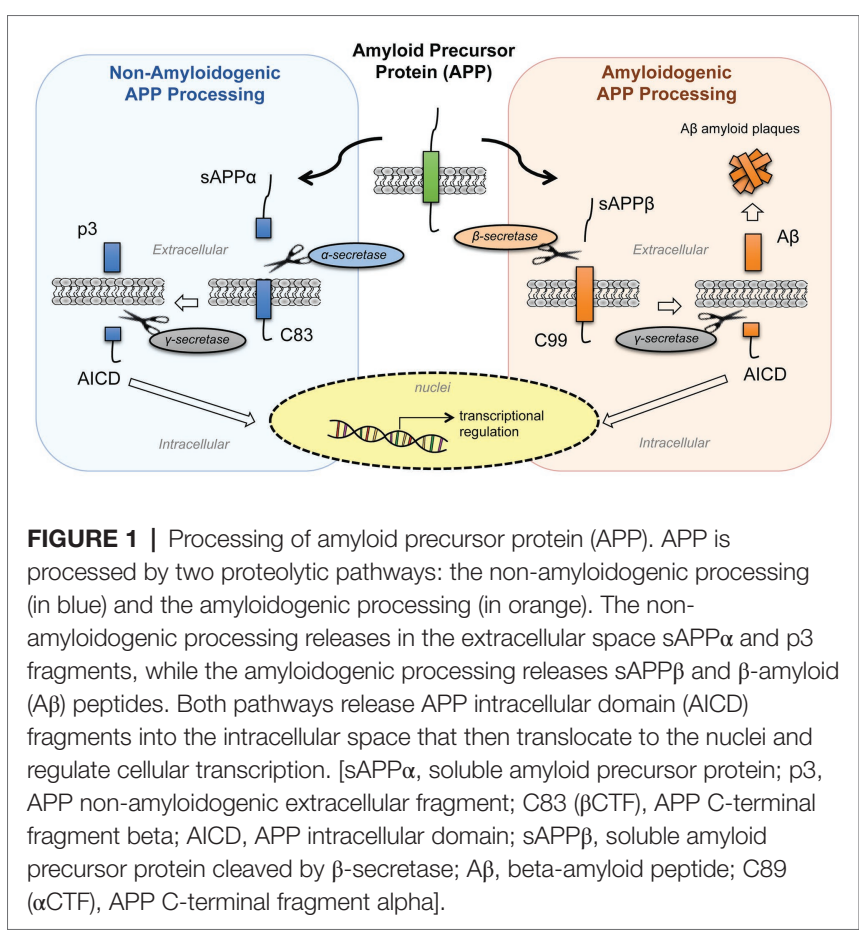


$\mathrm{AD}$ and $\mathrm{CAA}$ is well established, evidences show that activated endothelial cells and platelets are also able to release A $\beta 1-40$ peptides (Kitazume et al., 2012; Canobbio et al., 2015). Under normal physiological conditions, APP is predominantly processed through the non-amyloidogenic pathway, and the $\mathrm{A} \beta$ peptide is constitutively generated at relatively low levels. In addition, several mechanisms of $\mathrm{A} \beta$ clearance involving the cerebrovasculature contribute to maintain the concentrations of these peptides to physiological levels in the brain. Some of these mechanisms include $\mathrm{A} \beta$ degradation by proteolytic enzymes, phagocytosis by macrophages, intramural periarterial drainage, and receptor mediated $\mathrm{A} \beta$ transport across the $\mathrm{BBB}$ in which the main transport proteins are: the P-glycoprotein (P-gp), the low-density lipoprotein receptor related protein-1 (LRP-1), and the receptor for advanced glycation end-products (RAGE). While LRP-1 mediates the efflux of A $\beta$ from the brain to the blood circulation, RAGE plays an opposite role by promoting the influx to the brain, thus promoting its accumulation in the parenchyma (Deane et al., 2004; Wan et al., 2014; Wang et al., 2016). Impaired clearance of $A \beta$ across the cerebrovascular endothelium is considered the main cause of CAA (Qi and $\mathrm{Ma}, 2017)$. Recent studies suggested the involvement of heparan sulfate proteoglycans (HSPGs) in modulating A $\beta$ clearance and that the altered distribution and increased levels of HSPGs in $\mathrm{AD}$ brains might contribute to $\mathrm{A} \beta$ aggregation and plaque formation (Zhang et al., 2014; Liu et al., 2016). Interestingly, APP processing is influenced by its cellular distribution: the cell-surface accumulation of APP favors non-amyloidogenic processing (Jiang et al., 2014). On the contrary, the retention of APP in acidic compartments, such as early endosomes, promotes amyloidogenic processing (O’Brien and Wong, 2011). Furthermore, the soluble fragment $\mathrm{sAPP}-\alpha$ has a role in the auto regulation of APP processing. One of the proposed mechanisms is that the sAPP- $\alpha$ modulates BACE1 activity promoting the non-amyloidogenic process of APP, thus decreasing A $\beta$ production (Kaden et al., 2008; Gralle et al., 2009; Obregon et al., 2012). All cell types in the NVU express APP and release biologically active APP metabolites, however increasing evidence suggests that dysregulation of APP homeostasis in the brain vasculature would shift the balance toward pathological outcomes. In fact, reduced expression of APP in senescent brain microvascular endothelium contributes to downregulation of $\operatorname{sAPP} \alpha$ and promotes the amyloidogenic processing of APP, suggesting that aging-induced loss of APP function might increase the susceptibility to neurovascular dysfunction (Kern et al., 2006; Sun et al., 2018). Moreover, the amyloidogenic secretase BACE1 shows an age-related increased expression and activity in specific brain regions (e.g., cortex) in a mouse model, probably due to alterations of the cellular microenvironment (Chiocco and Lamb, 2007). Not only $\mathrm{A} \beta$ production but also its accumulation appears to follow an age-related specific regional pattern (e.g., leptomeningeal and parenchymal vessels), indicating age- and spatial-related efficiency of BBB mechanisms for $\mathrm{A} \beta$ clearance and degradation (Lewis et al., 2006; van Assema et al., 2012; Zoufal et al., 2020). Based on this evidence, the alteration of APP expression and processing affects the integrity and functionality of neurovascular tissues, and this may be a critical step in the pathogenesis of neurodegenerative diseases.

\section{APP AND CEREBRAL VASCULATURE}

APP is highly expressed in embryonic endothelium, suggesting an important role of this macromolecule and its metabolites in early angiogenesis (Ott and Bullock, 2001). A strong correlation between APP loss-of-function models and vascular dysfunction has been reported, supporting the importance of this protein and its metabolites on vascular homeostasis. In the zebrafish embryo, knockdown of APP by morpholino causes diffused angiogenic defects especially in the brain. This phenotype can be rescued by reintroducing $\mathrm{A} \beta$ peptides supporting the hypothesis that these peptides have an essential role in angiogenesis during embryonic development (Luna et al., 2013). Indeed, blocking $\mathrm{A} \beta$ production by inhibition of BACE1 or $\gamma$-secretase activity causes reduced angiogenesis both in vitro and in vivo (Paris et al., 2005). Several studies showed that APP exerts vascular protective properties under physiological conditions. APP regulates expression and function of endothelial nitric oxide synthase (eNOS) in cerebrovascular endothelium (d'Uscio et al., 2018). Loss of APP leads to a loss of eNOS protein expression and to an increase of oxidative stress both in vivo and in vitro models (d'Uscio et al., 2018; d'Uscio and Katusic, 2019). On the other hand, in $\mathrm{eNOS}^{+/-}$mouse model, reduced availability of endothelial $\mathrm{NO}$ leads to increased cerebrovascular concentrations of $\mathrm{A} \beta$ (Austin and Katusic, 2020) and transgenic mice overexpressing APP show increased oxidative stress and cerebrovascular dysfunction, associated with altered vasoactive signaling (Tong et al., 2005). In experimental models of stroke, the compensatory increase in cerebrovascular blood flow induced by the occlusion of the common carotid artery is attenuated in $\mathrm{APP}^{-/-}$mice (Koike et al., 2012). Due to this reduced ability to adjust blood flow, $\mathrm{APP}^{-/-}$mice die shortly after the common carotid artery occlusion, whereas wild-type mice survive. Conversely, in transgenic-AD rats, the overexpression of wild-type APP in neuronal tissue exerts neuroprotective effect from ischemic damage (Clarke et al., 2007). APP may also play a role in pathogenesis of atherosclerosis. $\mathrm{APP}$ and $\mathrm{A} \beta$ can be found in advanced human carotid plaques and in atherosclerotic aortas of Apolipoprotein E-deficient $\left(\mathrm{apoE}^{-/-}\right)$ mice, where the APP overexpression in this mouse model accelerates the development of aortic atherosclerotic (De Meyer et al., 2002; Austin et al., 2009; Tibolla et al., 2010). Moreover, transgenic B6Tg2576 mice overexpressing double Swedish mutated human APP (K670N/M671L) develop non-dietary induced early atherosclerotic (Li et al., 2003). On the contrary, the lack of APP attenuated atherogenesis and leads to plaque stability in double knockout mice $\mathrm{APP}^{-/-} / \mathrm{apoE}^{-/-}$(Van De Parre et al., 2011). A recent study suggested that the increased pulsatile stretch on the microvessel walls induced by hypertension functions as a mechanic stimulus that modifies the expression and processing of APP, promoting APP overexpression, and favoring APP amyloidogenic processing, and linking APP processing with hypertension (Gangoda et al., 2018). Moreover, modifications of vascular tone could be caused by an alteration of normal 
neurovascular coupling. Since components of the NVU, such as astrocytes and neurons, control vasodilation by releasing vasoactive molecules, altered vasomotor signals might affect APP processing in cerebral microvasculature (Niwa et al., 2001, 2002; Park et al., 2004, 2005). These studies suggest that several vascular risk factors are linked to APP dysfunction. Although the vascular function of APP has not been defined yet, these evidences suggest the importance of this protein on vascular development and on maintaining the normal tissue homeostasis.

\section{APP PHYSIOLOGICAL ROLES IN CEREBRAL VASCULATURE}

Several physiological roles have been attributed to APP and its processing products, some of which impact neurovascular development and function. Even if APP is notoriously known for its contribution to pathogenesis of neurodegenerative diseases, and many physiological roles have been identified in neural cells (Perez et al., 1997; Nicolas and Hassan, 2014; Nhan et al., 2015; Habib et al., 2017; Coronel et al., 2018), little is known on its function on endothelial cells and cerebral vasculature (Figure 2). Growing evidence suggests that perturbations of some of APP functional activities may contribute to cerebral angiopathy and neurodegeneration (Pearson and Peers, 2006; Thinakaran and Koo, 2008; d'Uscio et al., 2017; Muller et al., 2017). Studying APP cellular functions is complex since both the full-length protein and the secreted or intracellular metabolites have biological activity. The $\mathrm{A} \beta$ peptide appears to be involved in protecting the body from

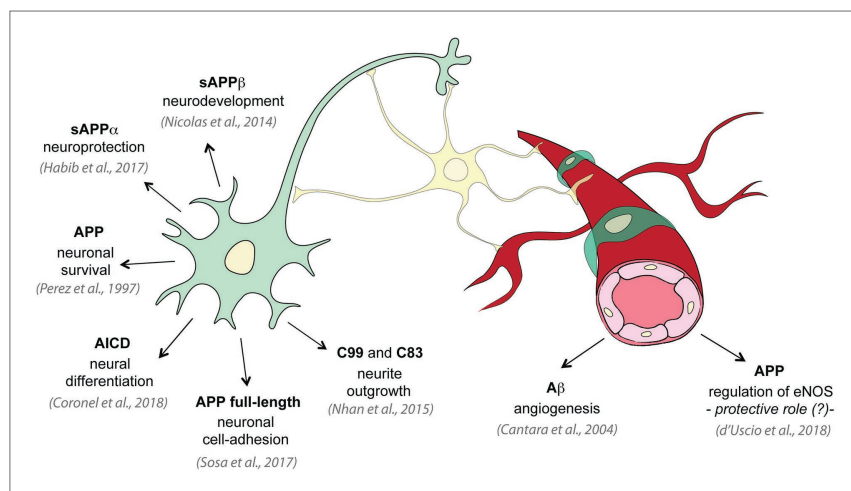

FIGURE 2 | Physiological roles of APP and its metabolites. Several studies investigated the physiological functions of APP on neural tissue: APP promotes neuron viability and axonogenesis (Perez et al., 1997); membrane APP full-length protein shows cell-adhesive properties in neurons (Sosa et al., 2017); sAPP $\alpha$ has been shown to be neuroprotective and to have neuronal trophic properties (Habib et al., 2017); sAPP $\beta$ is important for neuronal development (Nicolas and Hassan, 2014); C99 and C83 fragments are involved in neurite outgrowth (Nhan et al., 2015); AICD controls neural differentiation (Coronel et al., 2018). On the contrary only few studies investigated the physiological role of APP in vascular tissue: low concentrations of $A \beta$ promote endothelial cells migration and proliferation and angiogenesis (Cantara et al., 2004); and APP regulates expression of endothelial nitric oxide synthase (eNOS) and may exert a protective role (d'Uscio et al., 2018). various types of infections, sealing leaks in the BBB, improving outcomes after injury, and stimulating angiogenesis by modifying the response to angiogenic factors (Cantara et al., 2004; Brothers et al., 2018). Full-length APP protein has been suggested to function as an important factor for proper migration of neuronal precursors into the cortical plate during the development of mammalian brain (Young-Pearse et al., 2007). The secreted ectodomain SAPP- $\alpha$ is sufficient to rescue prominent deficits in $\mathrm{APP}^{-/-}$mice such as reduction in brain and body weight, impairment in spatial learning, and longterm potentiation (Ring et al., 2007). Moreover, different APP isoforms may have distinct roles in various cell types. While the intracellular C-terminus is conserved in all APP isoforms, the extracellular N-terminus of APP differs between isoforms. The endothelial-specific isoforms, APP751 and APP770, contain two conserved extracellular regions (E1 and E2) connected by an acidic domain (AcD), a Kunitz protease inhibitor (KPI) region, and an OX-2 antigen domain, while the neuronal isoform APP695 lacks the KPI and OX-2 domains. The $\mathrm{N}$-terminal of all APP isoforms presents functional binding sites for metals (zinc and copper) and extracellular matrix (ECM) proteins (heparin, collagen, and laminin; Zheng and Koo, 2011; van der Kant and Goldstein, 2015). Here, we summarize the physiological roles of APP full-length protein and its metabolites in cerebral vasculature.

\section{APP and Angiogenesis}

Many studies have clearly shown the detrimental role of A $\beta$ accumulation on vascular stability; however, evidences suggest that APP mediates endothelial cells' response to angiogenic growth factors and modulates angiogenesis. Different APP metabolites have been shown to have different roles in angiogenesis and vascular maintenance. A $\beta$ peptides, for example, show both anti-angiogenic and pro-angiogenic effects in a dose-dependent manner in vitro. In fact, high micromolar concentrations of different $\mathrm{A} \beta$ variants impair angiogenesis, while low nanomolar concentrations of either $A \beta 1-40$ or A $\beta 1-42$ promote angiogenesis in cultured cerebral and peripheral endothelial cells by promoting cell proliferation, migration, and tube formation (Cantara et al., 2004; Cameron et al., 2012). However, the role of $A \beta$ on angiogenesis in vivo is still controversial since cerebral hyper-vascularization was observed in human $\mathrm{AD}$ brains and transgenic animals overexpressing APP (Biron et al., 2011). To note, the majority of neo-formed vessels observed in $\mathrm{AD}$ is so called "string vessels," non-functional capillaries composed by connecting tissue and lacking endothelial cells (Brown, 2010; Forsberg et al., 2018). It has been proposed that the $A \beta$-induced aberrant angiogenesis may be the basis for $\mathrm{BBB}$ disruption in $\mathrm{AD}$ (Biron et al., 2011). A $\beta$ peptides can modulate angiogenesis by functionally interacting with important angiogenic signaling pathways, such as the FGF-2, the vascular endothelial growth factor (VEGF), and the notch signaling (Cantara et al., 2004; Patel et al., 2010; Cameron et al., 2012); however, in vivo and in vitro studies showed once again controversial results. While brains of patients with $\mathrm{AD}$ show upregulation of the VEGF suggesting an interaction of VEGF 
with APP processing (Burger et al., 2009), in vitro studies revealed that high concentrations of $\mathrm{A} \beta$ act as a VEGF antagonist, inhibiting VEGR receptor (VEGFR2) activation as well as VEGF-stimulated activation of eNOS in endothelium (Patel et al., 2010; Lamoke et al., 2015; Cho et al., 2017). Another APP metabolite, the secreted APP- $\alpha$ ectodomain, sAPP- $\alpha$, has been proposed to modulate angiogenesis by binding to the FGF-2 receptor (FGFR-1). In particular, sAPP- $\alpha$ may counterbalance $A \beta$ anti-angiogenic effect by competing with $\mathrm{A} \beta$ and FGF-2 for binding to FGFR-1 (Reinhard et al., 2013). More studies are needed to unravel the dichotomy of $\mathrm{A} \beta$ roles on angiogenesis and to establish the exact role of each APP metabolite on angiogenesis.

\section{APP and Cell Adhesion}

While the APP soluble metabolites act mostly as ligands, the APP full-length membrane protein functions as a membrane receptor and interacts with cell-adhesion molecules and the ECM. APP extracellular domain binds a series of ECM molecules, including collagen, spondin, laminin, reelin, and HSPGs (glypican and syndecans), and to cell adhesion molecules (CAMs) expressed in neighbor cells, suggesting an important function of APP as an adhesion molecule (Sosa et al., 2017). Many of these interactions stimulate neuronal migration and neurite outgrowth, and we can assume a similar function in endothelial cells (Sosa et al., 2017). The APP extracellular domain is also able to self-dimerize and bind to cell surface receptors, promoting APP surface localization (Deyts et al., 2016). As already discussed, cell-surface accumulation of APP favors non-amyloidogenic processing, thus cell-surface dimerization of APP as well as binding to ECM appears to modulate APP proteolytic processing by secretases. This suggests that APP-dependent adhesive contacts contribute to the control of the dynamics of APP extracellular and intracellular fragments generation. Moreover, APP connects the extracellular environment to the cellular cytoskeleton by physically linking ECM and CAMs elements to the actin cytoskeleton through intracellular scaffold proteins. The cytosolic region of APP presents a YENPTY amino acid sequence motif that is recognized by adaptor proteins (such as Fe65, Mint/X11, and Dab1) capable to link with the actin cytoskeleton and Eb41 (component of cortical cytoskeleton that directly interacts with alpha-actin). Based on this evidence, APP acts as a cell adhesion molecule; however, this physiological role in endothelial cells has not yet been explored.

\section{APP and Transcription Factors}

The AICD plays an important role as a transcriptional regulator and shares many structural and functional similarities with the receptor Notch, a key regulator of endothelial cell phenotype. The cleavage of APP by $\gamma$-secretase acts as a receptor processing of APP transmembrane region yielding the biologically active cytosolic fragment AICD that participates in cell signaling. This processing step is shared by many membrane-anchored proteins, included Notch (Kopan and Ilagan, 2004). AICD has a short half-life and is rapidly degraded resulting in low steady-state concentrations. Analogous to Notch receptor signaling, AICD regulates gene expression interacting with transcription factors. In particular, AICD interacts with Fe65 and Tip60 to form a transcriptionally active complex that has been reported to promote glycogen synthase kinase $3 \beta$ (GSK3 $\beta$ ) gene expression (Cao and Sudhof, 2001; Deyts et al., 2016). APP activates or inhibits GSK3 $\beta$ depending on its subcellular localization: The signaling associated with AICD transcription promotes GSK3 $\beta$ activation, while retaining AICD at the membrane favors inhibition of GSK3 $\beta$ signaling (Chang et al., 2006; Deyts et al., 2012). Dysregulation of GSK3 $\beta$ is involved in several aspects of $\mathrm{AD}$ development and progression, pointing out the importance of a correct regulation of APP interacting proteins (Llorens-Martin et al., 2014). Similar to the Notch intracellular domain (NICD), the AICD has been also found to regulate cellular calcium homeostasis through a $\gamma$-secretase dependent mechanism (Leissring et al., 2002; Hamid et al., 2007). Notch is an essential protein for endothelial cells, and Notch signaling controls fundamental aspects of angiogenic blood vessel growth and regulates vascular remodeling, vessels stabilization, and endothelial cells quiescence (Mack and Iruela-Arispe, 2018). Similarly, AICD may contribute to the stability of endothelial phenotype by modulating various APP physiological functions including trafficking and signal transduction. The complete understanding of AICD-mediated intracellular molecular mechanisms promoting vascular functionality and BBB integrity requires further investigation.

\section{CONCLUSION}

APP is a very complex protein that can function as a fulllength membrane protein but also through its processing metabolites (included A $\beta$ ). While the APP soluble metabolites function mostly as ligands, the APP full-length membrane protein functions as a membrane receptor and interacts with cell-adhesion molecules and the ECM. The processing of this protein through an amyloidogenic or non-amyloidogenic pathway is a key point for the development of amyloid deposits observed in $\mathrm{AD}$ and CAA. The failure of clinical trials targeting the amyloidogenic processing and $\mathrm{A} \beta$ clearance suggests that more effort is needed to understand the physiological function of APP and modulation of APP processing in cell homeostasis. Even if all cell types of the NVU express APP, experimental in vivo and in vitro evidence show that endothelial cells dysfunction is related to loss of vascular APP homeostasis. Vascular risk factors such as aging and hypertension can alter APP homeostasis in cerebrovascular tissue not only by modulating APP expression and processing but also by affecting APP protein interaction network. In conclusion, the loss of the physiological activity of APP and its metabolites may have a very important clinical significance. Understanding the influence of APP roles on the functionality of the vascular system might shed light on new therapeutic targets and provide a new perspective on treatment options of neurodegenerative diseases. 


\section{AUTHOR CONTRIBUTIONS}

ER wrote the manuscript. SD and MZ critically reviewed and edited the manuscript. All authors contributed to the article and approved the submitted version.

\section{REFERENCES}

Austin, S. A., and Katusic, Z. S. (2020). Partial loss of endothelial nitric oxide leads to increased cerebrovascular beta amyloid. J. Cereb. Blood Flow Metab. 40, 392-403. doi: 10.1177/0271678X18822474

Austin, S. A., Sens, M. A., and Combs, C. K. (2009). Amyloid precursor protein mediates a tyrosine kinase-dependent activation response in endothelial cells. J. Neurosci. 29, 14451-14462. doi: 10.1523/JNEUROSCI.3107-09.2009

Biron, K. E., Dickstein, D. L., Gopaul, R., and Jefferies, W. A. (2011). Amyloid triggers extensive cerebral angiogenesis causing blood brain barrier permeability and hypervascularity in Alzheimer's disease. PLoS One 6:e23789. doi: 10.1371/ journal.pone.0023789

Brothers, H. M., Gosztyla, M. L., and Robinson, S. R. (2018). The physiological roles of amyloid-beta peptide hint at new ways to treat Alzheimer's disease. Front. Aging Neurosci. 10:118. doi: 10.3389/fnagi.2018.00118

Brown, W. R. (2010). A review of string vessels or collapsed, empty basement membrane tubes. J. Alzheimers Dis. 21, 725-739. doi: 10.3233/JAD-2010-100219

Burger, S., Noack, M., Kirazov, L. P., Kirazov, E. P., Naydenov, C. L., Kouznetsova, E., et al. (2009). Vascular endothelial growth factor (VEGF) affects processing of amyloid precursor protein and beta-amyloidogenesis in brain slice cultures derived from transgenic Tg2576 mouse brain. Int. J. Dev. Neurosci. 27, 517-523. doi: 10.1016/j.ijdevneu.2009.06.011

Cai, W., Zhang, K., Li, P., Zhu, L., Xu, J., Yang, B., et al. (2017). Dysfunction of the neurovascular unit in ischemic stroke and neurodegenerative diseases: an aging effect. Ageing Res. Rev. 34, 77-87. doi: 10.1016/j.arr.2016.09.006

Cameron, D. J., Galvin, C., Alkam, T., Sidhu, H., Ellison, J., Luna, S., et al. (2012). Alzheimer's-related peptide amyloid-beta plays a conserved role in angiogenesis. PLoS One 7:e39598. doi: 10.1371/journal.pone.0039598

Canobbio, I., Abubaker, A. A., Visconte, C., Torti, M., and Pula, G. (2015). Role of amyloid peptides in vascular dysfunction and platelet dysregulation in Alzheimer's disease. Front. Cell. Neurosci. 9:65. doi: 10.3389/fncel.2015.00065

Cantara, S., Donnini, S., Morbidelli, L., Giachetti, A., Schulz, R., Memo, M., et al. (2004). Physiological levels of amyloid peptides stimulate the angiogenic response through FGF-2. FASEB J. 18, 1943-1945. doi: 10.1096/fj.04-2114fje

Cao, X., and Sudhof, T. C. (2001). A transcriptionally [correction of transcriptively] active complex of APP with Fe65 and histone acetyltransferase Tip60. Science 293, 115-120. doi: 10.1126/science.1058783

Chang, K. A., Kim, H. S., Ha, T. Y., Ha, J. W., Shin, K. Y., Jeong, Y. H., et al. (2006). Phosphorylation of amyloid precursor protein (APP) at Thr668 regulates the nuclear translocation of the APP intracellular domain and induces neurodegeneration. Mol. Cell. Biol. 26, 4327-4338. doi: 10.1128/MCB.02393-05

Chiocco, M. J., and Lamb, B. T. (2007). Spatial and temporal control of agerelated APP processing in genomic-based beta-secretase transgenic mice. Neurobiol. Aging 28, 75-84. doi: 10.1016/j.neurobiolaging.2005.11.011

Cho, S. J., Park, M. H., Han, C., Yoon, K., and Koh, Y. H. (2017). VEGFR2 alteration in Alzheimer's disease. Sci. Rep. 7:17713. doi: 10.1038/s41598-017-18042-1

Chou, C. H., Fan, H. C., and Hueng, D. Y. (2015). Potential of neural stem cell-based therapy for Parkinson's disease. Parkinsons Dis. 2015:571475. doi: $10.1155 / 2015 / 571475$

Clarke, J., Thornell, A., Corbett, D., Soininen, H., Hiltunen, M., and Jolkkonen, J. (2007). Overexpression of APP provides neuroprotection in the absence of functional benefit following middle cerebral artery occlusion in rats. Eur. J. Neurosci. 26, 1845-1852. doi: 10.1111/j.1460-9568.2007.05807.x

Coronel, R., Bernabeu-Zornoza, A., Palmer, C., Muniz-Moreno, M., Zambrano, A., Cano, E., et al. (2018). Role of amyloid precursor protein (APP) and its derivatives in the biology and cell fate specification of neural stem cells. Mol. Neurobiol. 55, 7107-7117. doi: 10.1007/s12035-018-0914-2

de la Torre, J. (2018). The vascular hypothesis of Alzheimer's disease: a key to preclinical prediction of dementia using neuroimaging. J. Alzheimers Dis. 63, 35-52. doi: 10.3233/JAD-180004

\section{FUNDING}

This review was supported by Italian Ministry of Education, University and Research (grant MIUR-PRIN n. 20152HKF3Z to $\mathrm{MZ}$ ).

De Meyer, G. R., De Cleen, D. M., Cooper, S., Knaapen, M. W., Jans, D. M., Martinet, W., et al. (2002). Platelet phagocytosis and processing of beta-amyloid precursor protein as a mechanism of macrophage activation in atherosclerosis. Circ. Res. 90, 1197-1204. doi: 10.1161/01.RES.0000020017.84398.61

Deane, R., Wu, Z., Sagare, A., Davis, J., Du Yan, S., Hamm, K., et al. (2004). LRP/amyloid beta-peptide interaction mediates differential brain efflux of Abeta isoforms. Neuron 43, 333-344. doi: 10.1016/j.neuron.2004.07.017

Deyts, C., Thinakaran, G., and Parent, A. T. (2016). APP receptor? To be or not to be. Trends Pharmacol. Sci. 37, 390-411. doi: 10.1016/j.tips.2016.01.005

Deyts, C., Vetrivel, K. S., Das, S., Shepherd, Y. M., Dupre, D. J., Thinakaran, G., et al. (2012). Novel GalphaS-protein signaling associated with membranetethered amyloid precursor protein intracellular domain. J. Neurosci. 32, 1714-1729. doi: 10.1523/JNEUROSCI.5433-11.2012

d'Uscio, L. V., He, T., and Katusic, Z. S. (2017). Expression and processing of amyloid precursor protein in vascular endothelium. Physiology 32, 20-32. doi: 10.1152/physiol.00021.2016

d'Uscio, L. V., He, T., Santhanam, A. V., and Katusic, Z. S. (2018). Endotheliumspecific amyloid precursor protein deficiency causes endothelial dysfunction in cerebral arteries. J. Cereb. Blood Flow Metab. 38, 1715-1726. doi: $10.1177 / 0271678 X 17735418$

d'Uscio, L. V., and Katusic, Z. S. (2019). Vascular phenotype of amyloid precursor protein-deficient mice. Am. J. Physiol. Heart Circ. Physiol. 316, H1297-H1308. doi: 10.1152/ajpheart.00539.2018

Forsberg, K. M. E., Zhang, Y., Reiners, J., Ander, M., Niedermayer, A., Fang, L., et al. (2018). Endothelial damage, vascular bagging and remodeling of the microvascular bed in human microangiopathy with deep white matter lesions. Acta Neuropathol. Commun. 6:128. doi: 10.1186/s40478-018-0632-z

Gangoda, S. V. S., Avadhanam, B., Jufri, N. F., Sohn, E. H., Butlin, M., Gupta, V., et al. (2018). Pulsatile stretch as a novel modulator of amyloid precursor protein processing and associated inflammatory markers in human cerebral endothelial cells. Sci. Rep. 8:1689. doi: 10.1038/s41598-018-20117-6

Gralle, M., Botelho, M. G., and Wouters, F. S. (2009). Neuroprotective secreted amyloid precursor protein acts by disrupting amyloid precursor protein dimers. J. Biol. Chem. 284, 15016-15025. doi: 10.1074/jbc.M808755200

Gustafsson, S., Gustavsson, T., Roshanbin, S., Hultqvist, G., Hammarlund-Udenaes, M., Sehlin, D., et al. (2018). Blood-brain barrier integrity in a mouse model of Alzheimer's disease with or without acute 3D6 immunotherapy. Neuropharmacology 143, 1-9. doi: 10.1016/j.neuropharm.2018.09.001

Habib, A., Sawmiller, D., and Tan, J. (2017). Restoring soluble amyloid precursor protein alpha functions as a potential treatment for Alzheimer's disease. J. Neurosci. Res. 95, 973-991. doi: 10.1002/jnr.23823

Hamid, R., Kilger, E., Willem, M., Vassallo, N., Kostka, M., Bornhovd, C., et al. (2007). Amyloid precursor protein intracellular domain modulates cellular calcium homeostasis and ATP content. J. Neurochem. 102, 1264-1275. doi: $10.1111 /$ j.1471-4159.2007.04627.x

Iadecola, C. (2017). The neurovascular unit coming of age: a journey through neurovascular coupling in health and disease. Neuron 96, 17-42. doi: 10.1016/j. neuron.2017.07.030

Jiang, S., Li, Y., Zhang, X., Bu, G., Xu, H., and Zhang, Y. W. (2014). Trafficking regulation of proteins in Alzheimer's disease. Mol. Neurodegener. 9:6. doi: 10.1186/1750-1326-9-6

Kaden, D., Munter, L. M., Joshi, M., Treiber, C., Weise, C., Bethge, T., et al. (2008). Homophilic interactions of the amyloid precursor protein (APP) ectodomain are regulated by the loop region and affect beta-secretase cleavage of APP. J. Biol. Chem. 283, 7271-7279. doi: 10.1074/jbc.M708046200

Kern, A., Roempp, B., Prager, K., Walter, J., and Behl, C. (2006). Down-regulation of endogenous amyloid precursor protein processing due to cellular aging. J. Biol. Chem. 281, 2405-2413. doi: 10.1074/jbc.M505625200

Kitazume, S., Yoshihisa, A., Yamaki, T., Oikawa, M., Tachida, Y., Ogawa, K., et al. (2012). Soluble amyloid precursor protein 770 is released from inflamed 
endothelial cells and activated platelets: a novel biomarker for acute coronary syndrome. J. Biol. Chem. 287, 40817-40825. doi: 10.1074/jbc.M112.398578

Klohs, J. (2020). An integrated view on vascular dysfunction in Alzheimer's disease. Neurodegener. Dis. 19, 109-127. doi: 10.1159/000505625

Koike, M. A., Lin, A. J., Pham, J., Nguyen, E., Yeh, J. J., Rahimian, R., et al. (2012). APP knockout mice experience acute mortality as the result of ischemia. PLoS One 7:e42665. doi: 10.1371/journal.pone.0042665

Kopan, R., and Ilagan, M. X. (2004). Gamma-secretase: proteasome of the membrane? Nat. Rev. Mol. Cell Biol. 5, 499-504. doi: 10.1038/nrm1406

Lamoke, F., Mazzone, V., Persichini, T., Maraschi, A., Harris, M. B., Venema, R. C., et al. (2015). Amyloid beta peptide-induced inhibition of endothelial nitric oxide production involves oxidative stress-mediated constitutive eNOS/ HSP90 interaction and disruption of agonist-mediated Akt activation. J. Neuroinflammation 12, 84. doi: 10.1186/s12974-015-0304-x

Leissring, M. A., Murphy, M. P., Mead, T. R., Akbari, Y., Sugarman, M. C., Jannatipour, M., et al. (2002). A physiologic signaling role for the gammasecretase-derived intracellular fragment of APP. Proc. Natl. Acad. Sci. U. S. A. 99, 4697-4702. doi: 10.1073/pnas.072033799

Lewis, H., Beher, D., Cookson, N., Oakley, A., Piggott, M., Morris, C. M., et al. (2006). Quantification of Alzheimer pathology in ageing and dementia: age-related accumulation of amyloid-beta(42) peptide in vascular dementia. Neuropathol. Appl. Neurobiol. 32, 103-118. doi: 10.1111/j.1365-2990.2006.00696.x

Li, L., Cao, D., Garber, D. W., Kim, H., and Fukuchi, K. (2003). Association of aortic atherosclerosis with cerebral beta-amyloidosis and learning deficits in a mouse model of Alzheimer's disease. Am. J. Pathol. 163, 2155-2164. doi: 10.1016/s0002-9440(10)63572-9

Liu, X., Hou, D., Lin, F., Luo, J., Xie, J., Wang, Y., et al. (2019). The role of neurovascular unit damage in the occurrence and development of Alzheimer's disease. Rev. Neurosci. 30, 477-484. doi: 10.1515/revneuro-2018-0056

Liu, C. C., Zhao, N., Yamaguchi, Y., Cirrito, J. R., Kanekiyo, T., Holtzman, D. M., et al. (2016). Neuronal heparan sulfates promote amyloid pathology by modulating brain amyloid-beta clearance and aggregation in Alzheimer's disease. Sci. Transl. Med. 8:332ra344. doi: 10.1126/scitranslmed.aad3650

Llorens-Martin, M., Jurado, J., Hernandez, F., and Avila, J. (2014). GSK-3beta, a pivotal kinase in Alzheimer disease. Front. Mol. Neurosci. 7:46. doi: 10.3389/ fnmol.2014.00046

Luna, S., Cameron, D. J., and Ethell, D. W. (2013). Amyloid-beta and APP deficiencies cause severe cerebrovascular defects: important work for an old villain. PLoS One 8:e75052. doi: 10.1371/journal.pone.0075052

Mack, J. J., and Iruela-Arispe, M. L. (2018). NOTCH regulation of the endothelial cell phenotype. Curr. Opin. Hematol. 25, 212-218. doi: 10.1097/ MOH.0000000000000425

Muller, U. C., Deller, T., and Korte, M. (2017). Not just amyloid: physiological functions of the amyloid precursor protein family. Nat. Rev. Neurosci. 18, 281-298. doi: 10.1038/nrn.2017.29

Nhan, H. S., Chiang, K., and Koo, E. H. (2015). The multifaceted nature of amyloid precursor protein and its proteolytic fragments: friends and foes. Acta Neuropathol. 129, 1-19. doi: 10.1007/s00401-014-1347-2

Nicolas, M., and Hassan, B. A. (2014). Amyloid precursor protein and neural development. Development 141, 2543-2548. doi: 10.1242/dev.108712

Niwa, K., Kazama, K., Younkin, L., Younkin, S. G., Carlson, G. A., and Iadecola, C. (2002). Cerebrovascular autoregulation is profoundly impaired in mice overexpressing amyloid precursor protein. Am. J. Physiol. Heart Circ. Physiol. 283, H315-H323. doi: 10.1152/ajpheart.00022.2002

Niwa, K., Porter, V. A., Kazama, K., Cornfield, D., Carlson, G. A., and Iadecola, C. (2001). A beta-peptides enhance vasoconstriction in cerebral circulation. Am. J. Physiol. Heart Circ. Physiol. 281, H2417-H2424. doi: 10.1152/ajpheart.2001.281.6.H2417

Nizari, S., Carare, R. O., Romero, I. A., and Hawkes, C. A. (2019). 3D reconstruction of the neurovascular unit reveals differential loss of cholinergic innervation in the cortex and hippocampus of the adult mouse brain. Front. Aging Neurosci. 11:172. doi: 10.3389/fnagi.2019.00172

Nortley, R., Korte, N., Izquierdo, P., Hirunpattarasilp, C., Mishra, A., Jaunmuktane, Z., et al. (2019). Amyloid beta oligomers constrict human capillaries in Alzheimer's disease via signaling to pericytes. Science 365:eaav9518. doi: $10.1126 /$ science.aav9518

Obregon, D., Hou, H., Deng, J., Giunta, B., Tian, J., Darlington, D., et al. (2012). Soluble amyloid precursor protein-alpha modulates beta-secretase activity and amyloid-beta generation. Nat. Commun. 3:777. doi: 10.1038/ ncomms 1781
O’Brien, R. J., and Wong, P. C. (2011). Amyloid precursor protein processing and Alzheimer's disease. Annu. Rev. Neurosci. 34, 185-204. doi: 10.1146/ annurev-neuro-061010-113613

Ott, M. O., and Bullock, S. L. (2001). A gene trap insertion reveals that amyloid precursor protein expression is a very early event in murine embryogenesis. Dev. Genes Evol. 211, 355-357. doi: 10.1007/s004270100158

Paris, D., Quadros, A., Patel, N., DelleDonne, A., Humphrey, J., and Mullan, M. (2005). Inhibition of angiogenesis and tumor growth by beta and gammasecretase inhibitors. Eur. J. Pharmacol. 514, 1-15. doi: 10.1016/j.ejphar.2005.02.050

Park, L., Anrather, J., Forster, C., Kazama, K., Carlson, G. A., and Iadecola, C. (2004). Abeta-induced vascular oxidative stress and attenuation of functional hyperemia in mouse somatosensory cortex. J. Cereb. Blood Flow Metab. 24, 334-342. doi: 10.1097/01.WCB.0000105800.49957.1E

Park, L., Anrather, J., Zhou, P., Frys, K., Pitstick, R., Younkin, S., et al. (2005). $\mathrm{NADPH}$-oxidase-derived reactive oxygen species mediate the cerebrovascular dysfunction induced by the amyloid beta peptide. J. Neurosci. 25, 1769-1777. doi: 10.1523/JNEUROSCI.5207-04.2005

Patel, N. S., Mathura, V. S., Bachmeier, C., Beaulieu-Abdelahad, D., Laporte, V., Weeks, O., et al. (2010). Alzheimer's beta-amyloid peptide blocks vascular endothelial growth factor mediated signaling via direct interaction with VEGFR-2. J. Neurochem. 112, 66-76. doi: 10.1111/j.1471-4159.2009.06426.x

Pearson, H. A., and Peers, C. (2006). Physiological roles for amyloid beta peptides. J. Physiol. 575, 5-10. doi: 10.1113/jphysiol.2006.111203

Perez, R. G., Zheng, H., Van der Ploeg, L. H., and Koo, E. H. (1997). The beta-amyloid precursor protein of Alzheimer's disease enhances neuron viability and modulates neuronal polarity. J. Neurosci. 17, 9407-9414. doi: 10.1523/JNEUROSCI.17-24-09407.1997

Qi, X. M., and Ma, J. F. (2017). The role of amyloid beta clearance in cerebral amyloid angiopathy: more potential therapeutic targets. Transl. Neurodegener. 6:22. doi: 10.1186/s40035-017-0091-7

Reinhard, C., Borgers, M., David, G., and De Strooper, B. (2013). Soluble amyloid-beta precursor protein binds its cell surface receptor in a cooperative fashion with glypican and syndecan proteoglycans. J. Cell Sci. 126, 4856-4861. doi: $10.1242 /$ jcs. 137919

Ring, S., Weyer, S. W., Kilian, S. B., Waldron, E., Pietrzik, C. U., Filippov, M. A., et al. (2007). The secreted beta-amyloid precursor protein ectodomain APPs alpha is sufficient to rescue the anatomical, behavioral, and electrophysiological abnormalities of APP-deficient mice. J. Neurosci. 27, 7817-7826. doi: 10.1523/ JNEUROSCI.1026-07.2007

Shariati, S. A., and De Strooper, B. (2013). Redundancy and divergence in the amyloid precursor protein family. FEBS Lett. 587, 2036-2045. doi: 10.1016/j. febslet.2013.05.026

Sosa, L. J., Caceres, A., Dupraz, S., Oksdath, M., Quiroga, S., and Lorenzo, A. (2017). The physiological role of the amyloid precursor protein as an adhesion molecule in the developing nervous system. J. Neurochem. 143, 11-29. doi: $10.1111 /$ jnc. 14122

Stakos, D. A., Stamatelopoulos, K., Bampatsias, D., Sachse, M., Zormpas, E., Vlachogiannis, N. I., et al. (2020). The Alzheimer's disease amyloid-beta hypothesis in cardiovascular aging and disease: JACC focus seminar. J. Am. Coll. Cardiol. 75, 952-967. doi: 10.1016/j.jacc.2019.12.033

Sun, R., He, T., Pan, Y., and Katusic, Z. S. (2018). Effects of senescence and angiotensin II on expression and processing of amyloid precursor protein in human cerebral microvascular endothelial cells. Aging 10, 100-114. doi: 10.18632/aging. 101362

Thinakaran, G., and Koo, E. H. (2008). Amyloid precursor protein trafficking, processing, and function. J. Biol. Chem. 283, 29615-29619. doi: 10.1074/ jbc.R800019200

Tibolla, G., Norata, G. D., Meda, C., Arnaboldi, L., Uboldi, P., Piazza, F., et al. (2010). Increased atherosclerosis and vascular inflammation in APP transgenic mice with apolipoprotein E deficiency. Atherosclerosis 210, 78-87. doi: 10.1016/j.atherosclerosis.2009.10.040

Tong, X. K., Nicolakakis, N., Kocharyan, A., and Hamel, E. (2005). Vascular remodeling versus amyloid beta-induced oxidative stress in the cerebrovascular dysfunctions associated with Alzheimer's disease. J. Neurosci. 25, 11165-11174. doi: 10.1523/JNEUROSCI.4031-05.2005

van Assema, D. M., Lubberink, M., Boellaard, R., Schuit, R. C., Windhorst, A. D., Scheltens, P., et al. (2012). P-glycoprotein function at the blood-brain barrier: effects of age and gender. Mol. Imaging Biol. 14, 771-776. doi: 10.1007/ s11307-012-0556-0 
Van De Parre, T. J., Guns, P. J., Fransen, P., Martinet, W., Bult, H., Herman, A. G., et al. (2011). Attenuated atherogenesis in apolipoprotein E-deficient mice lacking amyloid precursor protein. Atherosclerosis 216, 54-58. doi: 10.1016/j. atherosclerosis.2011.01.032

van der Kant, R., and Goldstein, L. S. (2015). Cellular functions of the amyloid precursor protein from development to dementia. Dev. Cell 32, 502-515. doi: 10.1016/j.devcel.2015.01.022

Van Nostrand, W. E., Schmaier, A. H., Neiditch, B. R., Siegel, R. S., Raschke, W. C., Sisodia, S. S., et al. (1994). Expression, purification, and characterization of the kunitz-type proteinase inhibitor domain of the amyloid beta-protein precursor-like protein-2. Biochim. Biophys. Acta 1209, 165-170. doi: 10.1016/0167-4838(94)90180-5

Wan, W., Chen, H., and Li, Y. (2014). The potential mechanisms of Abetareceptor for advanced glycation end-products interaction disrupting tight junctions of the blood-brain barrier in Alzheimer's disease. Int. J. Neurosci. 124, 75-81. doi: 10.3109/00207454.2013.825258

Wang, W., Bodles-Brakhop, A. M., and Barger, S. W. (2016). A role for P-glycoprotein in clearance of Alzheimer amyloid beta-peptide from the brain. Curr. Alzheimer Res. 13, 615-620. doi: 10.2174/1567205013666160314151012

Wilhelm, I., Nyul-Toth, A., Suciu, M., Hermenean, A., and Krizbai, I. A. (2016). Heterogeneity of the blood-brain barrier. Tissue Barriers 4:e1143544. doi: 10.1080/21688370.2016.1143544

Young-Pearse, T. L., Bai, J., Chang, R., Zheng, J. B., LoTurco, J. J., and Selkoe, D. J. (2007). A critical function for beta-amyloid precursor protein in neuronal migration revealed by in utero RNA interference. J. Neurosci. 27, 14459-14469. doi: 10.1523/JNEUROSCI.4701-07.2007

Zhang, G. L., Zhang, X., Wang, X. M., and Li, J. P. (2014). Towards understanding the roles of heparan sulfate proteoglycans in Alzheimer's disease. Biomed. Res. Int. 2014:516028. doi: 10.1155/2014/516028

Zheng, H., and Koo, E. H. (2011). Biology and pathophysiology of the amyloid precursor protein. Mol. Neurodegener. 6:27. doi: 10.1186/ 1750-1326-6-27

Zoufal, V., Wanek, T., Krohn, M., Mairinger, S., Filip, T., Sauberer, M., et al. (2020). Age dependency of cerebral P-glycoprotein function in wild-type and APPPS1 mice measured with PET. J. Cereb. Blood Flow Metab. 40, 150-162. doi: 10.1177/0271678X18806640

Conflict of Interest: The authors declare that the research was conducted in the absence of any commercial or financial relationships that could be construed as a potential conflict of interest.

Copyright (c) 2020 Ristori, Donnini and Ziche. This is an open-access article distributed under the terms of the Creative Commons Attribution License (CC BY). The use, distribution or reproduction in other forums is permitted, provided the original author(s) and the copyright owner(s) are credited and that the original publication in this journal is cited, in accordance with accepted academic practice. No use, distribution or reproduction is permitted which does not comply with these terms. 